\section{A penchant for protists}

Laurence D. Hurst

Tracing the History of Eukaryotic Cells: The Enigmatic Smile. By Betsey Dexter Dyer and Robert Alan Obar. Columbia University Press: 1994 . Pp. 259. \$30, £20 (pbk); $\$ 65, £ 43$ (hbk)

THE vast menagerie of early eukaryotes that constitute the Protista is as bizarre an array of the weird and wonderful as can be imagined: from organisms without sex but which nevertheless alternate ploidy, to others that are parasitized by their sister species and almost everything in between . While God, as J. B. S. Haldane once ventured, must have "an inordinate fondness for beetles", I suspect that the Deity has also, at the very least, a penchant for protists.

The mind-boggling assortment is not just a curiosity. In the details of protist biology may also lie clues to the origins and evolution of eukaryotes. Just as the Cheshire cat vanished leaving only its smile, so too history leaves a scar on present-day descendants. It is these enigmatic fragments that Dyer and Obar seek to tease out.

Names, dates, births and marriages are as important in understanding eukaryotic history as they are for more conventional history. For the events that the authors discuss, the fossil record is useful for estimating dates, whereas molecular data are making significant inroads into reconstructing the family tree of unicellular life. Unfortunately, as the authors note, data from a few key eukaryotic groups are missing and, as is almost inevitable, there is disagreement over the phylogeny. This problem is compounded by a turbulent nomenclature (a turbulence typified, for instance, by this reviewer's frequent conflation of protist with protoctist). But Dyer and Obar treat all the terminological entanglement pragmatically and do not let the muddle obscure the information.

For the history of the eukaryotes, however, it is the marriages that are most noteworthy. Although only 25 years ago it was considered unorthodox and largely vilified, the idea that most eukaryotic cells are a union between symbiont and host is now almost unquestioned orthodoxy, at least for the ancestry of plastids and mitochondria. Today's problems, well reviewed by the authors, are numbering the independent origins and deciding which organelles are symbiotically derived and from which taxa.

Although the symbiogenic hypothesis had old roots, the acceptance of the idea is in large part due to the advocacy of Lynn Margulis. Some of her zeal has transferred to her students, Dyer and Obar. Although they would clearly be delighted if certain organelles could be shown to have sym- biotic origins, they usually balance their enthusiasm with words of caution and present the alternative arguments. A useful discussion of the types of data that can be used to examine the symbiogenic hypothesis is provided. They leave, however, a nagging loose end, the issue of whether in principle the origin of most organelles can ever be resolved.

Consider for instance the authors' new hypothesis for a symbiotic derivation of microtubule organizing centres (MTOC). By what information will the hypothesis live or die? Dyer and Obar argue, quite correctly, that an absence of MTOCassociated DNA would be evidence neither for nor against a symbiogenic origin: it may never have been there or it could have been transferred to the nucleus. So what is good evidence? That some prokaryotes may have proteins resembling those in the MTOC is not itself conclusive. It may be explained as convergence, the product of symbiosis, of horizontal gene transfer, or may simply reflect nuclear genome ancestry. The reason we can be fairly certain of mitochondrial and plastid origin is that so many facts point to the same end. For organelles without DNA the ancestry might, I regret, evade a convincing resolution.

For every history, names, dates and family trees are only part of the story. There is also the narrative, the enigmatic 'why?'. Why, for instance, did sex and sexes evolve and why were symbiotic relationships so successful? Testing explanations of some of these problems may be as hard as resolving issues of organelle origin. This is particularly true for events that happened only once. Suggestive patterns do however exist. Many of the major events in prokaryote and eukaryote evolution are, for instance, coincident with changes in atmospheric content. Although the authors provide stimulating speculation as to what this might mean, we are left with possibles, maybes and, quite often, no clear means to resolve the uncertainties.

The prospect is, however, less bleak for phenomena that have multiple evolutions. With an adequate phylogeny, independent evolutionary events can be resolved and phylogenetic contrasts sought. If, instead of apparently meaningless diversity, we are to have patterns, then this, the comparative method, seems the best analysis available. Some discussion of the methodology would then have been welcome, as would mention of attempts to perform such analysis. In several instances, no doubt for want of space, the underlying evolutionary genetic models also go unacknowledged. I can, however, only concur with the authors' plea for more work on protist biology. I must also concur with their admiration for the most recent compilation of knowledge, the remarkable Handbook of Protoctista edited by Margulis et al. (Jones and Bartlett, 1991), possibly her second great contribution to science. With an updated copy of this in one hand and a well resolved phylogeny in the other, we may soon have answers to many of the burning questions not only of early eukaryote history but also of evolution in general.

Laurence D. Hurst is in the Department of Genetics, University of Cambridge, Downing Street, Cambridge CB2 3EH, UK.

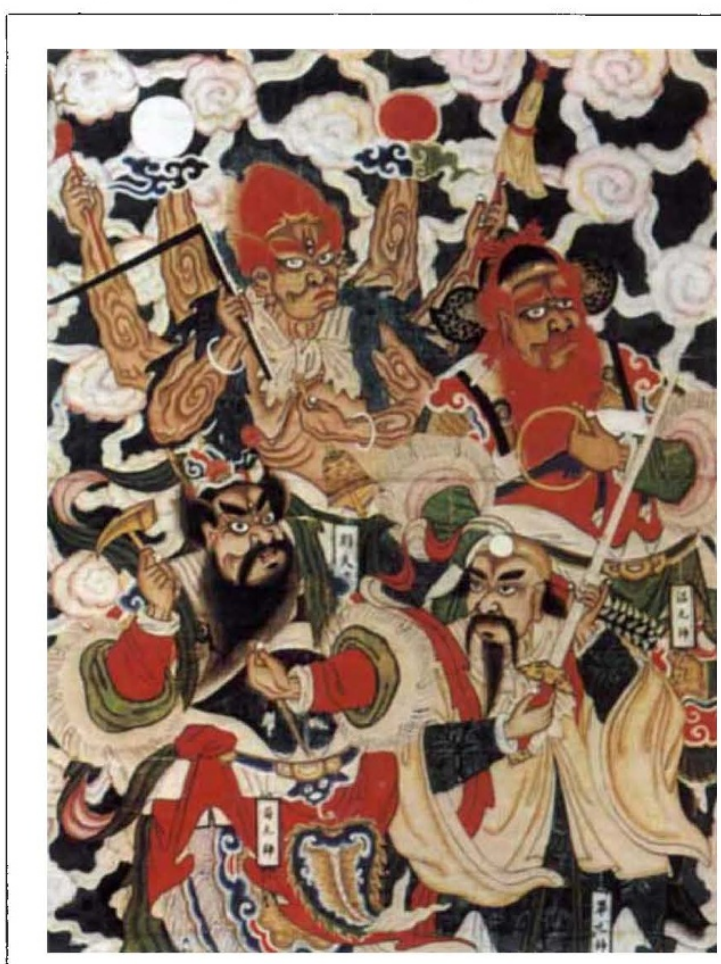

PART of a temple scroll showing four Daoist genii. From the cover of The Shorter Science and Civilisation in China: 4, an abridgement by Colin A. Ronan of Joseph Needham's monumental work. The fourth volume covers advances in mechanical engineering in early and mediaeval China. Cambridge University Press, £40, \$19.95 (hbk); £19.95, \$34.95 (pbk). 